\title{
A NOVEL ELECTRON SOLVATION PHENOMENON IN MOLTEN POTASSIUM THIOCYANATE
}

\author{
K. TENNAKONE \\ Department of Pbysics, University of Rubuna, Matara, Sri Lanka. \\ (Date of receipt : 03 July 1985) \\ (Date of acceptance : 22 April 1986)
}

\begin{abstract}
Potassium thiocyanate when heated above the melting point is found to acquire a bright blue color that deepens with increase of temperature. Optical absorption spectra and electronic conductivity measurements indicate that this phenomenon results from thermal generation of solvated electrons. A simple theory is given to correlate the observations.
\end{abstract}

\section{Introduction}

Polarons the 'self-trapped' electrons in an ionic lattice, whose existence first postulated by Landau, 12 having resolved many problems in condensed matter physics, 1,15 continue to arouse the interest of workers in a number of different fields. $6,16,17$ Now it is well established that polarons are also formed in molecular solids ${ }^{1}$ liquids $^{9,25}$ and gases. ${ }^{13,18}$ The best known systems where solvated electrons (polarons in a liquid are commonly referred to as solvated electrons) exist are solutions of alkali metals in liquid ammonia. 3,14,22,25 When these metals are dissolved in liquid $\mathrm{NH}_{3}$, the solution acquires a blue color. Absorption spectra, electronic transport and phase transitions observed here can all be explained on the assumption that alkali metal atoms dissociate in to ions and solvated electrons. $3,14,22,25$

In this letter we report our experimental results and theoretical interpretation of a novel phenomenon observed in molten potassium thiocyanate, that could be explained as due to thermal generation of solvated electrons.

\section{Experimental}

We have observed that KCNS heated well above the m.p ( $\simeq 446 \mathrm{~K}$ ) gradually acquires a bright blue color that deepens with the increase of temperature. The effect is completely reversible provided the heating is carried in vacuum and the decomposition temperature $(\sim 773 \mathrm{~K})$ is not exceeded. The optical absorption spectrum of the molten salt at different temperatures is given in Figure 1. It is seen that the spectrum has a broad absorption band with a 


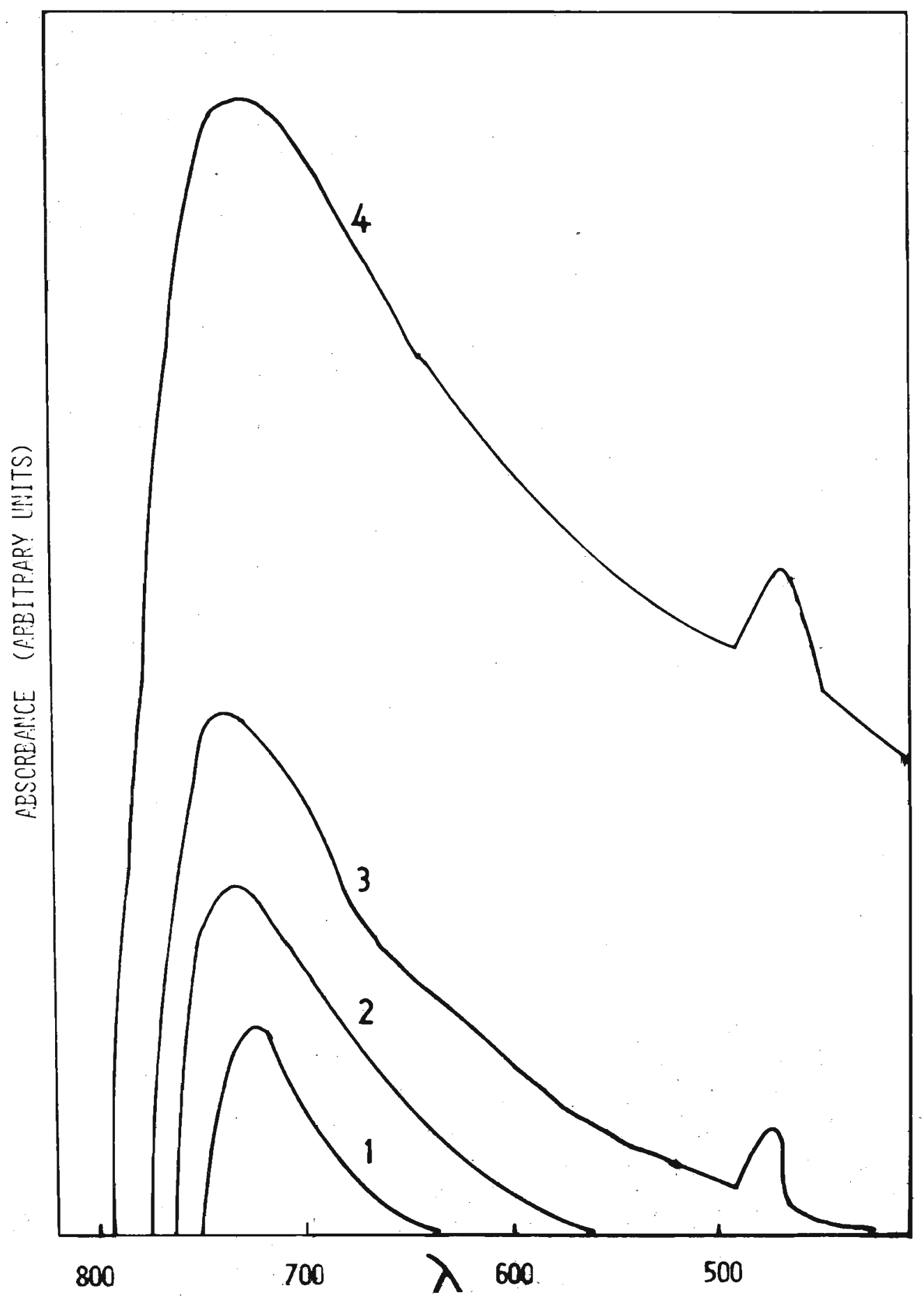

Figure 1. Absorption spectra of molten KCNS resulting from solvated electrons $\begin{array}{lllll}\text { (1) } 523 \mathrm{~K} & \text { (2) } 548 \mathrm{~K} & \text { (3) } 573 \mathrm{~K} & \text { (4) } 623 \mathrm{~K} \text {. The small peak near } 475 \mathrm{~nm}\end{array}$ comes from the (CNS) ${ }^{-2}$ ion $(\lambda$ in $\mathrm{nm})$. 
A novel electron solvation phenomenon in molten potassium thiocyanate 261

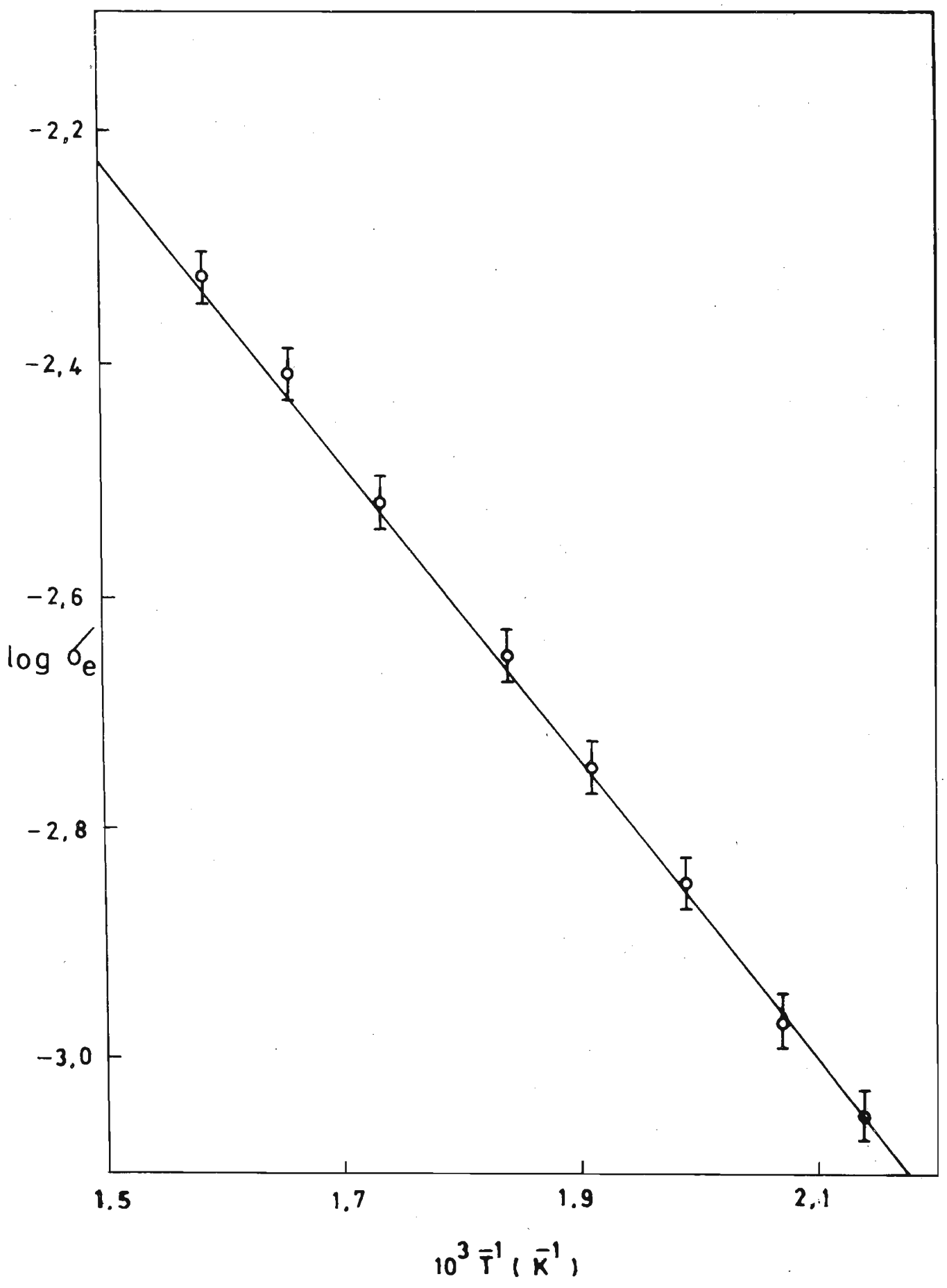

Figure 2. Plot of $\log \sigma_{\mathrm{e}}\left(\Omega^{-1} \mathrm{~cm}^{-1}\right)$ vs $\mathrm{T}^{-1}$. 


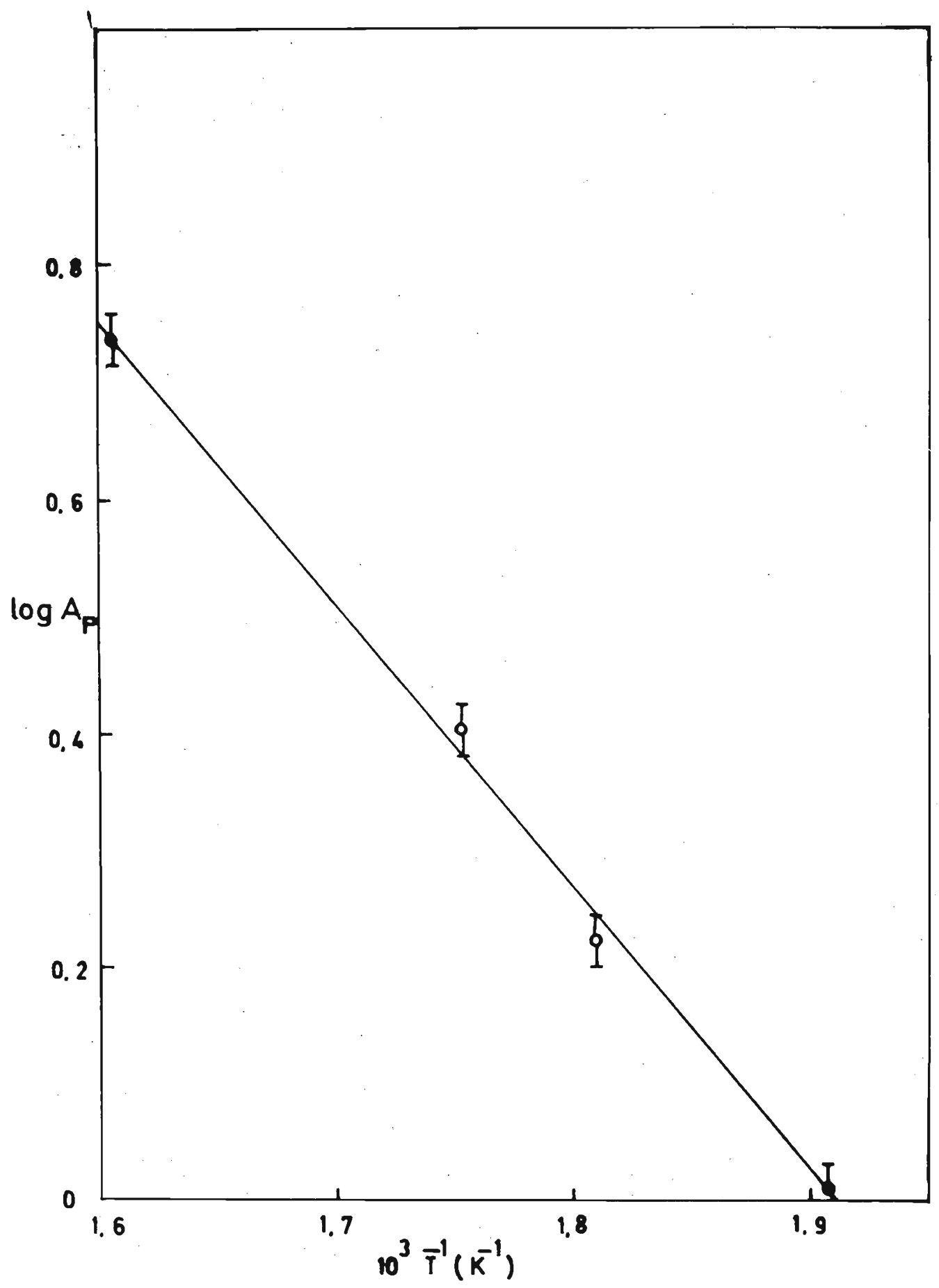

Figure 3. Plot of $\log A_{p}$ (peak absorbance $A_{p}$ in arbitrary units) vs $\mathrm{f}^{-1}$. 
sharp edge at low energies and a long tail towards the high energy region characteristic to absorption spectra of solvated electrons..$^{3,9,14,22,25}$ The position of the absorption peak and to a lesser extent the absorption edge is largely independent of temperature. However the peak absorbance $\left(\mathrm{A}_{\mathrm{p}}\right)$, very rapidly increases with temperature.

\section{Results}

We have found that at high temperatures (473-773K) molten KCNS becomes a very good electronic conductor. The plot of $\log \sigma_{e}\left(\sigma_{\mathrm{e}}\right.$ is the electronic conductivity measured by the polarization method) $)^{4,23} \mathrm{vs} \mathrm{T}^{-1}$ is found to fit into a straight line with an activation energy $23.1 \mathrm{~kJ} \mathrm{~mol}^{-1}$ (Figure 2). Furthermore the plot of $\log A_{p}$ vs $T^{-1}$ is also a straight line (Figure 3) with almost identical slope, ie, the relation,

$$
A_{p}=A_{o p} \operatorname{Exp}(-E / k T)
$$

is satisfied with $\mathrm{E}$ $\mathrm{T}=$ Temperature)

$0.25 \mathrm{eV} .\left(\mathrm{A}_{\mathrm{op}}=\right.$ constant, $\mathrm{k}=$ Boltzmann constant,

It is possible to give a simple theory to explain the above observations. We propose that the solvated electrons are thermally generated by ionization of $\mathrm{CNS}^{-}$ions. If $\mathrm{A}$ is the electron affinity of thiocyanogen (CNS), the energy I needed to ionize $\mathrm{CNS}^{-}$into a CNS molecule and a solvated electron is,

$$
\mathrm{I}=-\mathrm{A}+\mathrm{B} \text {, }
$$

where $\mathrm{B}$ is the binding energy of the solvated electron (note that the ionization energy is lower when a solvated rather than a free electron is formed). Thus the concentration $\mathrm{N}$ of the solvated electrons in thermal equilibrium is given by, $* 11$

$$
\mathrm{N} \simeq \mathrm{C} \operatorname{Exp}(-\mathrm{I} / 2 \mathrm{kT})
$$

where $\mathrm{C}$ depending weakly on $\mathrm{T}$ may be regarded approximately constant ${ }^{11}$ in the temperature range involved and the electronic conductivity resulting from the solvated electrons is,

$$
\epsilon_{\mathrm{e}} \simeq \mathrm{C} \mu \mathrm{e} \operatorname{Exp}(-\mathrm{I} / 2 \mathrm{kT})
$$

where $\mu$ is the mobility of the solvated electron. The mobility could vary with $\mathrm{T}$ according to the Nerst - Einstein type relation, ${ }^{14,15}$ but here again,

- The calculation of the equilibrium concentration in this case is completely equivalent to thermal ionisation of charge carriers from donor levels in a semiconductor. 
the $\mathrm{T}$ dependence of the term in front of the exponential factor in (4) is not very significant. Hence the plots of $\log A_{p}\left(A_{p}\right.$ is proportional to $\left.N\right) v^{-1} T^{-1}$ and $\log \quad \delta_{\mathrm{e}}$ vs $\mathrm{T}^{-1}$ should have the same slope as observed and we deduce that $\mathrm{I} \simeq 0.48 \mathrm{eV}$. The observed electron affinity of a CNS molecule in vacuum ${ }^{17}, 18$ is $200.8 \mathrm{~kJ} \mathrm{~mol}^{-1}$, hence from (1) we obtain $\mathrm{B} \simeq 1.69 \mathrm{eV}$ and the peak is expected to occur at $\lambda_{\mathrm{p}} \simeq \mathrm{hc} / \mathrm{B} \simeq 735 \mathrm{~nm}$. The observed value lies between $715-750 \mathrm{~nm}$, agreeing quite well with the predicted value.

Yet another observation that supports the idea we have proposed is the detection of (CNS) ${ }_{2}^{-}$ions formed by combination of thermally generated $\mathrm{CNS}$ with $\mathrm{CNS}^{-}$. The $(\mathrm{CNS})_{2}^{-}$ions are known to have characteristic absorption peak at $\sim 475 \mathrm{~nm}$.' We have noted that molten KCNS has an absorption peak centered near this point (Figure 1).

The effect is rather insensitive to common impurities other than water. However in all experiments we have used KCNS purified by several recrystallizations. Solvated electrons are highly reactive; water, oxygen and certain other impurities tend to induce some decomposition if the salt is kept in the molten state $(473-673 \mathrm{~K})$ for prolonged intervals. Again it is interesting to note that $\mathrm{NaCNS}$ having a higher melting point $(\sim 523 \mathrm{~K})$ exhibits the same phenomenon with almost identical features.

Several attempts have been made to construct models to interpret the detailed structure of the absorption spectra of solvated electrons. ${ }^{2,5,8,10,21}$ Most of them are based on the assumption that the electron experiences a coulomb like potential, ${ }^{2,3,5,8,10,21,25}$

$$
\mathrm{V}(\mathrm{r})=\mathrm{e}^{2}\left(\mathrm{~K}_{\bar{\alpha}}^{-1}-\mathrm{K}_{\mathrm{s}}^{-1}\right) \mathrm{r}^{-1}
$$

where $\mathrm{K}_{\alpha}, \mathrm{K}_{\mathrm{S}}$ are the optical and static dielectric constants of the liquid, for molten KCNS $(473-573 \mathrm{~K})$, we have noted $\mathrm{K}_{\alpha} \simeq 1.5$ and $\mathrm{K}_{\mathrm{s}} \simeq 3.3$ and the hydrogenic ionization energy turns out to be $\sim 172.8 \mathrm{~kJ} \mathrm{~mol}^{-1}$ $(1 \mathrm{~s}-2 \mathrm{p}$, transition energy $\sim 1.4 \mathrm{eV})$.

\section{Conclusions}

Though not in good quantitative agreement, the slight shift of the absorption edge towards the red region (Figure 1) with the increase of temperature could result from decrease of $\hat{K}_{s}$ with the increase of temperature. However, none of the above arguments are sufficient to explain all features in the absorption profile.

\footnotetext{
- In these models it is uncertain whether, the binding energy is to be taken as ionization energy or 1s - 2p transition energy.
} 
Molten KCNS is even a more vivid example of electron solvation than liquid ammonia. Further studies on this easily observed effect could elucidate electron trapping and other equally fascinating problems in molten salt systems. $^{24}$

\section{References}

1. AUSTIN, I. G. \& MOTT, N. F. (1969) Adv. Phys. $15: 41$;

2. BANERJEE, A. \& SIMONS, J. (1978) J. Chem. Phys. 68 : 415.

3. CATTERALl, R. \& MOTT, N. F. (1969) Adv. Pbys. 18 : 665;

4. CHANDRA, S. (1981) Superionic Solids North-Holland, Amsterdam .

5. COPELAND, D. A., KESTNER, N. R. \& JORTNER, J. (1970) J. Chem. Pbys. 53 : 1189.

6. EMIN, D. (1982) Phys. Today 35, No. 6, 34.

7. FOX, M. (1975) Concepts of Inorganic Photochemistry Wiley Interscience .

8. FRANK, J. \& PLATZMAN, R. (1954) Z. Phys. $138: 411$.

9. HART, E. J. \& ANBAR, M. (1970) The bydrated Electron Wiley, New York.

10. JORTNER, J. (1959) J. Chem. Phys. $30: 839$.

11. KITTEL, C. (1971) Introduction to Solid State Physics 4th ed. (John Wiley, New York) p.376.

12. LANDAU, L. D. (1933) Phys. Z. Sowjet. 3 : 664.

13. LEVINE, J. L. \& SANDERS, T. M. (1962) Phys. Rev. Lett. $8: 159$.

14. MOTT, N. F. (1974) Metal - Insulator Transitions Taylor \& Francis, London pp. $237-252$.

15. MOTT, N. F. \& DAVIS, E. A. (1979) Electronic Processes in Non-crystalline Materials 2nd ed. Clarendon Press, Oxford .

16. NACHTRIEB, N. H. (1975) Adv. Chem. Phys. $31: 465$.

17. NEFF, H., SASS, J. K., LEWRENZ, H. J. \& IBACH, H. (1980) J. Phys. Chem. 84 : 1135. 
18. NORTHBY, J. A. \& SANDERS, T. M. (1967) Pbys. Rev. Lett. 18 : 1184

19. PRITCHARD, H. O. (19.53) Chem. Rev. $52: 52$

20. Rubber Hand Book, (1973) 59th Edition, ed. by R. C. Weast C R C Press, Florida .

21. STEIN, G. \& TREININ, A. (1958) Trans. Faraday. Soc., $54: 338$.

22. THOMPSON, J.C. (19.76) Electrons in Liquid Ammonia Oxford, London .

23. WAGNER, J. B. \& WAGNER, C. (1957) J. Chem. Phys. 26:1597.

24. WARREN, W. W. Jr., SOTIER, S. \& BRENNERT, G. F. (1983) Pbys. Rev. Lett. $50: 1505$.

25. WEBSTER, B. C. (1979) Annual Reports on the Progress of Chemistry, Vol .76 Royal Society of Chemistry, London . 